\title{
Cardiac response to mental arithmetic under quiet and white noise distraction
}

WILLIAM G. STEELE, ${ }^{1,2}$ THE FELS RESEARCH INSTITUTE, Yellow Springs, Ohio AND PAUL B. KOONS, Jr., OHIO UNIVERSITY, Athens, Ohio

Cardiac responses to a mental arithmetic task were recorded with two background conditions: quiet and with a distracting white noise. The cardiac response to the mental arithmetic task was cardiac acceleration. The increase during the distracting condition was significantly higher than the increase during the quiet condition. These results were predicted from Lacey's theoretical formulations.

Lacey, Kagan, Lacey, \& Moss (1963) have proposed that cardiac responses are not only concomitant with but facilitative to the intended transaction between the individual and his environment.

In their report, Lacey et al (1963) present as an heuristic theoretical interpretation of their data the following formulation: "....we (have) proposed that cardiac deceleration accompanied and perhaps even facilitated ease of 'environmental intake' whereas cardiac acceleration accompanied or even facilitated 'rejection of the environment' [pp. 164-165]."

Data which substantiate this formulation are presented, and these findings have been independently replicated by Obrist (1963).

In his recent report, Lacey (1967) has emphasized that the cardiac response is dependent upon the objective environmental situation and the subjective "intent" of the individual. This is what is meant by Lacey's term, situational sterotypy.

Lacey (1967) presents data to support the position that cardiac function may exert some control of the central nervous system with cardiac accelerations being cortically inhibiting, thus facilitating internal mental elaboration or mental work, and cardiac deceleration activating the central nervous system and thus facilitating detection of environmental stimuli.

Gibson \& Hall (1967) were interested in the effects of task duration and task intensity or difficulty within two environmental background conditions. They report that "there was no evidence that mental work alone is a sufficient condition for acceleration or deceleration of heart rate."

There are many reports in the literature that deal with the effects of extraneous stimulation upon performance. In an early review, Bills (1937) had summarized the situation by stating that no prediction at all was possible for any particular set of experimental conditions. Investigation continues to focus on this problem but with little more success than reported by Bills (1937).

Gibson \& Yonas (1966) report that verbal distraction did not affect a visual scanning task performed by both college-age $S s$ and by third-grade Ss. Similar findings where performance has not been changed by distraction have been reported in a wide variety of situations (Woodhead, 1966; Barker \& Madell, 1965).

None of these investigators measured cardiac function, which would have been sensitive to the distractions.

The present experiment tested two hypotheses derived from Lacey's formulation. First, the cardiac response to a mental arithmetic task will be acceleration of the heart rate, and, second, the acceleration will be greater if mental arithmetic is performed in a distracting environment than if performed in a quiet environment.

Method. Fifteen young adults, 10 females and five males, ranging from 19 through 26 years of age volunteered as Ss. Heart rate (ECG) was measured while Ss were at rest (the base period), during a 1-min alert period (alert), and during the $2 \mathrm{~min}$ of mental arithmetic computation (the stimulation period). Each $S$ performed the arithmetic under both quiet and white noise background conditions.

All Ss were initially instructed that they would perform a mental arithmetic task under the quiet and noise background conditions. Beckman silver-silver-chloride electrodes were then attached for ECG recording and a $5 \mathrm{~min}$ rest was begun before recording the $1 \mathrm{~min}$ of base heart rate data. During the rest and base Ss were instructed to sit quietly, eyes closed, and relax. Ss were instructed at the beginning of the alert period: "In 1 min you will be given some mental arithmetic problems to solve. Concentrate only on their solution."

At the end of the alert time, the stimulation period began with the oral delivery of the first arithmetic problem to be solved. As $\mathbf{S}$ announced his answer, he was given another problem. All problems used the paradigm: a two digit number multiplied by a one digit number, plus a two digit number. All Ss received the same problems but in an individual, randomized order. At the end of the stimulation, Ss were again given a $5 \mathrm{~min}$ rest and the procedure repeated. Seven Ss had the quiet background stimulation condition first and eight Ss had the white noise background condition first.

All instructions and the white noise were recorded and presented through floor speakers in the $S$ room. The arithmetic problems were presented over an intercom. The white noise, which varied continuously between 50 and $90 \mathrm{~dB}$, was generated with a Grason-Stadler noise generator.

Results. Two measures of heart rate were used to describe the heart rate level: the mean maximum and the mean minimum heart rates. These are defined, respectively, as the mean of the 12 fastest heart beats for the maximum heart rate and the mean of the 12 slowest beats for the minimum heart rate. These measures were calculated for each of the three experimental periods for each $S$.

Differences in the cardiac response were determined by calculating the signed difference between the heart rate measures under the two different stimulus conditions. These differences were

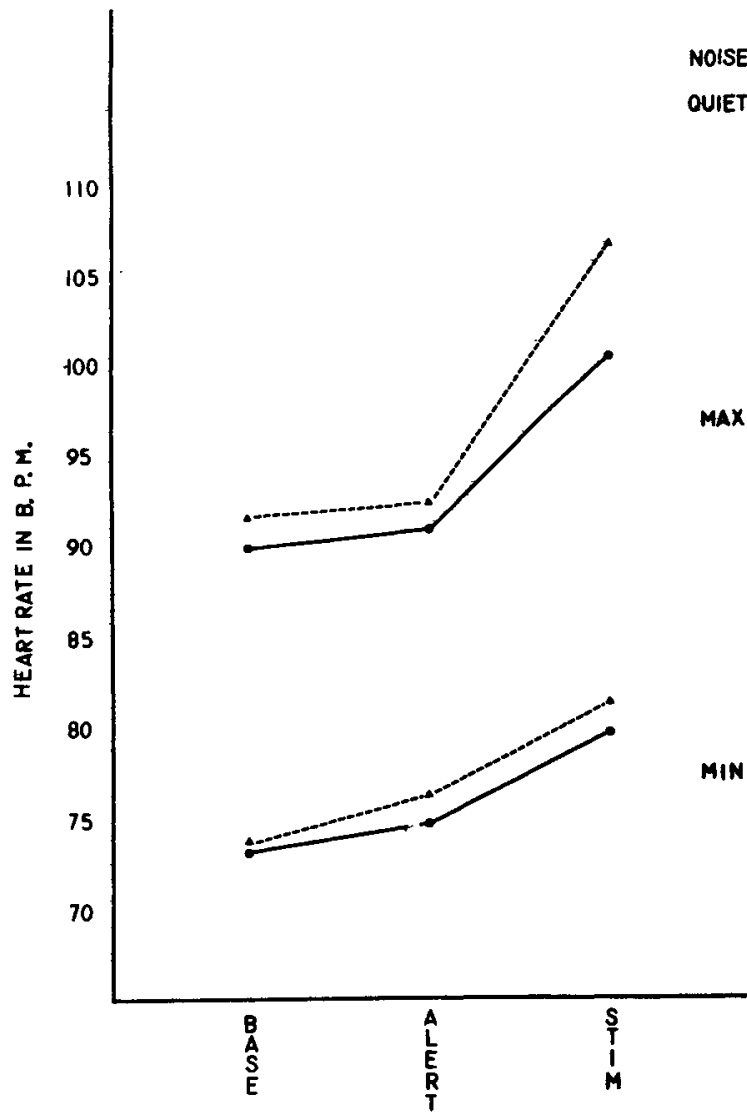

Fig. 1. The mean heart rate of the 12 maximum and the 12 minimum heart beats per min in each of the three experimental periods: the base, the alert, and the stimulation. 
evaluated by means of Wilcoxon's paired replicates test.

Figure 1 presents the average maximum and minimum heart rate for each of the experimental periods. The predicted cardiac response of acceleration during mental arithmetic is clearly seen and the maximum heart rate is significantly greater with the distraction than without. ( $p<.05$ Wilcoxon paired replicates test).

All of the base to stim and alert-to-stim differences showed significant accelerations $(\mathrm{p}<.02$ Wilcoxon's paired replicates test).

Discussion. Experimental evidence is presented which supports the hypotheses based upon Lacey's theoretical formulation. Cardiac acceleration does occur while the individual is engaged in the solution of mental arithmetic problems.

The cardiac acceleration is greater in the presence of an external distracting stimulus, supporting the position that increases in heart rate are involved in the individual's rejection of environmental stimuli.

Coquery \& Lacey (1966) have reported data showing that in a reaction time study where Ss had to get information-when to respond-increases in cardiac deceleration were associated with faster reaction times. Thus, there are experimental data to support Lacey's position.

\section{REFERENCES}

BAKER, R. W., \& MADELL, T. P. Susceptibility to distraction in academically underachieving and achieving male college students. $J$. consult. Psychol., 1965, 29, 173-177.

BILLS, A. G. Facilitation and inhibition in mental work. Psychol. Bull.,
$1937,34,286-309$.

COQUERY, J., \& LACEY, J. I. The effect of foreperiod duration on the components of the cardiac response during the foreperiod of a reactiontime experiment. Paper delivered at the Annual Meeting of the Society for Psychophysiological Research, October, 1966.

GIBSON, D., \& HALL, MARIA K. Cardiovascular change and mental task gradient. Psychon, Sci., 1966, 6, 245-246.

GIBSON, ELEANOR J. \& YONAS, A. A developmental study of the effects of visual and auditory interference on a visual scanning task. Psychon. Sci., 1966, 5, 163-164.

LACEY, J. I. Somatic response patterning and stress: Some revisions of activation theory. In $\mathrm{R}$. Trumbull (Ed.), Psychological stress: Issue in research. New York: Appleton-Century-Crofts, 1967.

LACEY, J. I., KAGAN, J., LACEY, BEATRICE C., \& MOSS, H. A. The visceral level; Situational determinants and behavioral correlates of autonomic response patterns. In P. H. Knapp (Ed.), Expressions of the emotions in man. New York: International Universities Press, 1963.

OBRIST, P. Cardiovascular differentiation of sensory stimuli. Psychosom. Med., 1963, 25, 450-459.

WOODHEAD, MURIEL M. An effect of noise on the distribution of attention. J. appl Psychol., 1966, 4, 296-299.

\section{NOTES}

1. This manuscript is based in part on a thesis submitted in partial fulfillment for the degree of Master of Science, Ohio University, March 16, 1968.

2. This research was supported in part by Grant. No. HD-00868 from the National Institute of Mental Health, U. S. Public Health Service. 